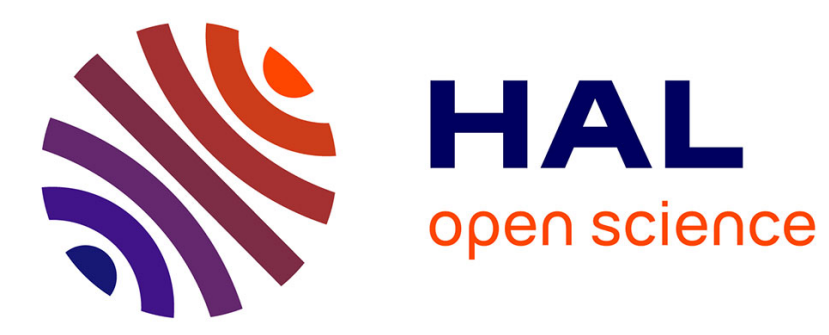

\title{
FREQUENCY DISPERSION OF THE PROTON ZEEMAN SPIN-LATTICE RELAXATION IN THE SMECTIC PHASES OF TBBA
}

\author{
R. Blinc, M. Luzar, M. Mali, R. Osredkar, J. Seliger, M. Vilfan
}

\section{- To cite this version:}

R. Blinc, M. Luzar, M. Mali, R. Osredkar, J. Seliger, et al.. FREQUENCY DISPERSION OF THE PROTON ZEEMAN SPIN-LATTICE RELAXATION IN THE SMECTIC PHASES OF TBBA. Journal de Physique Colloques, 1976, 37 (C3), pp.C3-73-C3-76. 10.1051/jphyscol:1976311 . jpa00216494

\author{
HAL Id: jpa-00216494 \\ https://hal.science/jpa-00216494
}

Submitted on 1 Jan 1976

HAL is a multi-disciplinary open access archive for the deposit and dissemination of scientific research documents, whether they are published or not. The documents may come from teaching and research institutions in France or abroad, or from public or private research centers.
L'archive ouverte pluridisciplinaire HAL, est destinée au dépôt et à la diffusion de documents scientifiques de niveau recherche, publiés ou non, émanant des établissements d'enseignement et de recherche français ou étrangers, des laboratoires publics ou privés. 


\title{
FREQUENCY DISPERSION OF THE PROTON ZEEMAN SPIN-LATTICE RELAXATION IN THE SMECTIC PHASES OF TBBA
}

\author{
R. BLINC, M. LUZAR, M. MALI, R. OSREDKAR \\ J. SELIGER and M. VILFAN \\ J. Stefan Institute, University of Ljubljana, Ljubljana, Yugoslavia
}

\begin{abstract}
Résumé. - Une méthode de cyclage de champs a permis d'étudier la dépendance en fréquence du temps de relaxation spin-réseau $\left(T_{1}\right)$ des protons dans les phases smectiques $\mathrm{A}, \mathrm{C}, \mathrm{B}$, et VII du Téréphtal-bis-butylaniline (TBBA). La plage de variation de la fréquence de Larmor $\omega_{\text {L }} s$ 'étend de 0,14 à $90 \mathrm{MHz}$. En phase smectique $T_{1}$ varie comme $\omega_{L}^{1 / 2}$ à haute fréquence et on dévie à basse fréquence ; ceci peut être expliqué par l'existence de fluctuations orientationnelles du type nématique en smectique $\mathrm{A}$ et par le couplage entre les ordres nématique et smectique.
\end{abstract}

Abstract. - Using a field cycling technique, the Larmor frequency $\left(v_{\mathrm{L}}\right)$ dependence of the proton Zeeman spin-lattice relaxation time $T_{1}$ has been measured in the smectic $\mathrm{A}$, smectic $\mathrm{C}$, smectic $\mathrm{B}$ and smectic VII phases of terephtal-bis-butylaniline (TBBA) between $v_{\mathrm{L}}=90 \mathrm{MHz}$ and $v_{\mathrm{L}}=0.14 \mathrm{MHz}$ and a significant dispersion has been found. The observed $\omega_{\mathrm{L}}^{1 / 2}$ dispersion law in the smectic A phase and the deviations from it at low frequencies can be explained by nematic director fluctuations in the smectic $A$ phase and the coupling between nematic and smectic order.

Whereas the nuclear spin-lattice relaxation mechanisms in nematic liquid crystals have been the subject of many investigations [1-6], very little is known about the nature of the spin-lattice relaxation process in smectic systems [3]. In this letter we report what we believe to be the first extended measurements of the Larmor frequency dependence of the proton spin-lattice relaxation time $T_{1}$ in the smectic $\mathrm{A}$, smectic $\mathrm{C}$, smectic $B_{\mathrm{c}}(H)$ and smectic VII phases [7]. The system investigated was terephtal-bis-butylaniline (TBBA). The results show that collective order fluctuations dominate the spin-lattice relaxation process in the smectic A phase and produce a characteristic frequency dispersion of $T_{1}$.

The measurements were performed in the magnetic field range between $H=21.4 \mathrm{kG}$

$$
\left(v_{\mathrm{L}}=\frac{\omega_{\mathrm{L}}}{2 \pi}=90 \mathrm{MHz}\right)
$$

and $H=33 \mathrm{G}\left(v_{\mathrm{L}}=0.14 \mathrm{MHz}\right)$ using a NMR field cycling technique. The sample, which had been polarized in a strong magnetic field $H_{0}$, is moved with the help of a pneumatic post to a lower field $H$, where it is allowed to relax for a time $t$. After that the sample is moved back to the field $H_{0}$, and the free induction decay signal, following a $90^{\circ}$ radiofrequency pulse of frequency $\omega_{0}=\gamma H_{0}$, is measured as a function of $t$ and $H$. The spin-lattice relaxation time $T_{1}$ is then evaluated from

$M(t)=M_{0}\left(1-H / H_{0}\right) \exp \left(-t / T_{1}\right)+M_{0} H / H_{0}$.

The obtained results $T_{1}=T_{1}(H)$ are shown in figure 1. A significant frequency $\left(\omega_{\mathrm{L}}=\gamma H\right)$ dispersion

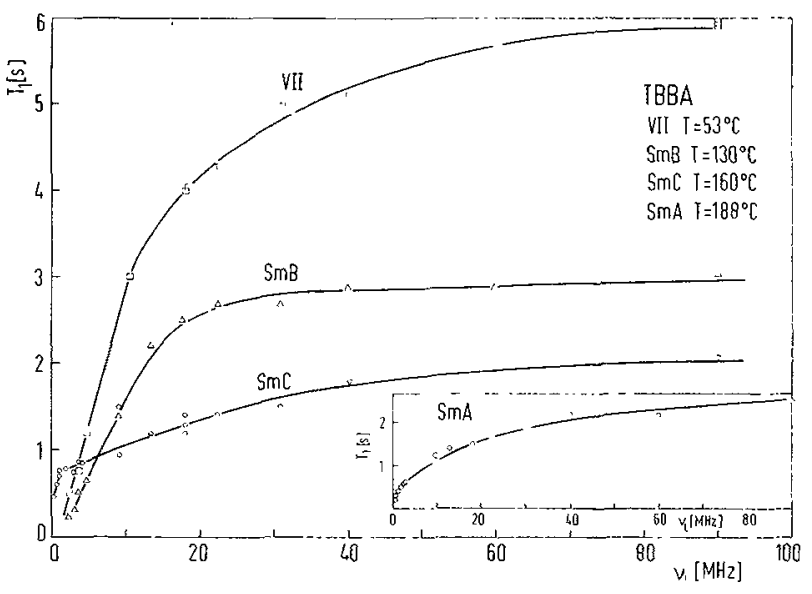

Fig. 1. - Larmor fequency dependence of the proton $T_{1}$ in the various smectic liquid crystalline phases of an unoriented sample of TBBA.

of the Zeeman proton spin-lattice relaxation time $T_{1}$ is evident in all four investigated smectic phases. Starting from $H=33 \mathrm{G}, T_{1}$ at first strongly increases with increasing $H$ and then gradually levels off. The levelling off occurs at a field which is much higher than the local dipolar field. The dispersion thus does not represent a transition from the dipolar to the Zeeman relaxation rate [8], but rather reflects the inherent molecular dynamics of these smectic phases.

The shape of the $T_{1}=T_{1}(H)$ dispersion curves in the smectic $\mathrm{A}$ and smectic $\mathrm{C}$ phases is quite different from that obtained in the smectic $B_{\mathrm{c}}(H)$ and VII phases. In these last two phases which are intermediate [7] between the crystalline state and the two dimensional liquid - like smectic A and smectic C 
mesophases, the low frequency $T_{1}$ is roughly proportional to the square of the Larmor frequency, $T_{1} \propto \omega_{\mathrm{L}}^{2}$, whereas the high frequency $T_{1}$ is nearly frequency independent in the saturation region. Whereas the dispersion in the smectic $B_{\mathrm{c}}(H)$ and VII phases may be thus describable as a superposition of two sets of random processes, a fast one $\left(\omega_{\mathrm{L}} \tau_{f, i} \ll 1\right)$ and a slow one $\left(\omega_{\mathrm{K}} \tau_{\mathrm{s}, i} \gg 1\right)$

$$
\begin{aligned}
T_{1}^{-1}=\left(T_{1}^{-1}\right)_{\mathrm{f}}+\left(T_{1}^{-1}\right)_{\mathrm{s}}=\sum_{i} & C_{1, i} \tau_{\mathrm{f}, i}+ \\
& +\sum_{i} C_{2, i} /\left(\omega_{\mathrm{L}}^{2} \tau_{\mathrm{s}, i}\right)
\end{aligned}
$$

representing, for instance, hindered rotations of molecular groups [9], this is certainly not the case for the smectic A and smectic C phases. Here the low frequency $T_{1}$ is proportional to $\omega_{\mathrm{L}}^{n}$ with $n \approx \frac{1}{2}$ rather than 2 , and there is no frequency independent saturation region at high fields as in the smectic $B$ phase. This demonstrates that collective rather than random processes determine $T_{\hat{1}}$.

As it can be seen from figure 2, the frequency dispersion of $T_{1}$ in the smectic A phase is in excellent agree-

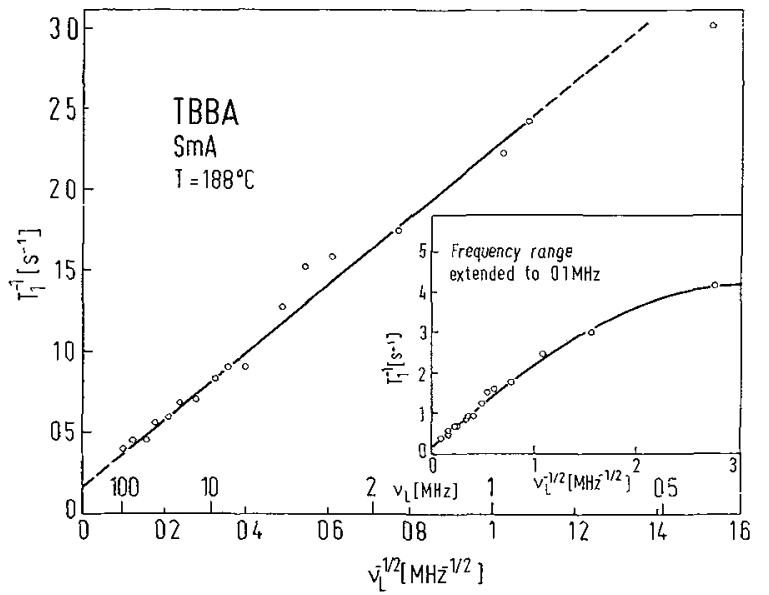

FIG. 2. - Proton Zeeman spin-lattice relaxation rate in the smectic A phase of an unoriented sample of TBBA as a function of the inverse square root of the Larmor frequency. The full line is the theoretical result according to expression (11) with $\omega_{\mathrm{c} 1}=\omega_{\mathrm{c} 2}=0.19 \mathrm{MHz}$.

ment with the nematic order director fluctuation (ODF) $《 \omega_{\mathrm{L}}^{1 / 2} »$ law [1] in the whole range between $21.4 \mathrm{kG}$ and $100 \mathrm{G}$ :

$$
\left(T_{1}^{-1}\right)=A / \sqrt{v_{\mathrm{L}}}+B .
$$

The angular dependence [10] of $T_{1}^{-1}$ at $60 \mathrm{MHz}$ (Fig. 3) on an oriented sample as well agrees with the one expected for order director fluctuations [10] and can be described by:

$$
\left(T_{1}^{-1}\right)=C \frac{1}{\sqrt{v_{\mathrm{L}}}} \cdot f(A)+B
$$

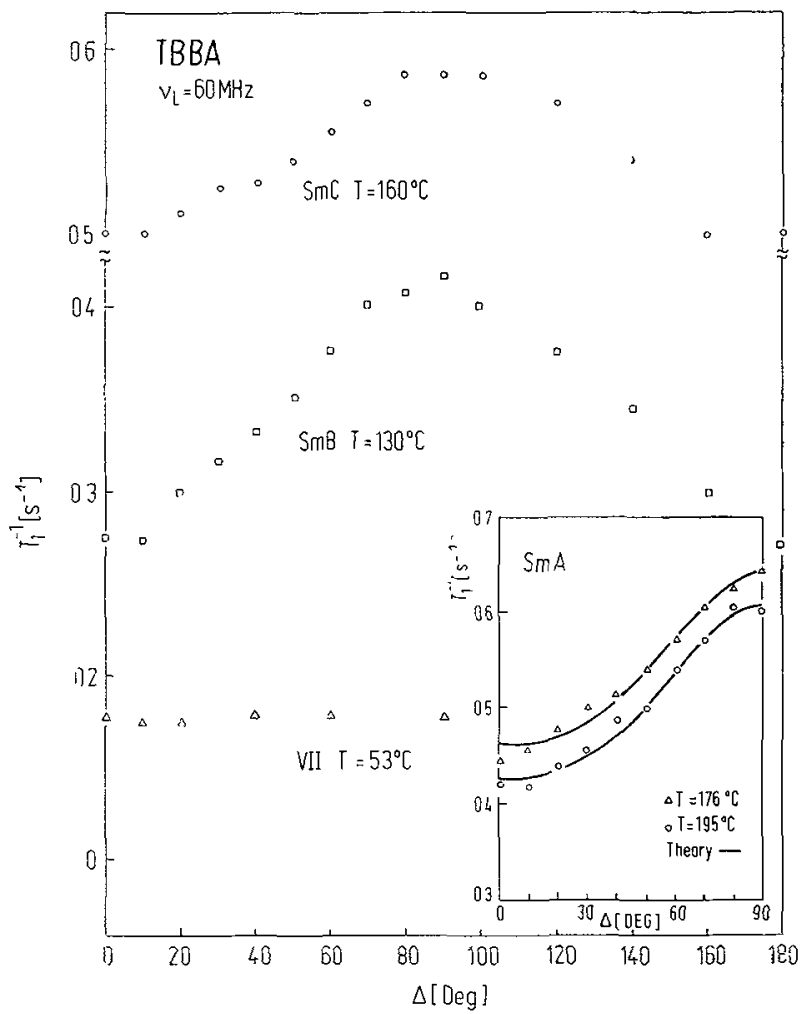

FIG. 3. - Angular dependence of the proton Zeeman spinlattice relaxation rate in the various smectic phases of TBBA as obtained on cooling the sample from the nematic phase in a high magnetic field. The full line is the theoretical angular dependence as obtained from eq. (11) and (4).

where

$$
\begin{aligned}
f(\Delta)=0.5\left(1-3 \cos ^{2} \Delta+4 \cos ^{4} \Delta\right) & + \\
+ & \frac{2}{\sqrt{2}}\left(1-\cos ^{4} \Delta\right),
\end{aligned}
$$

$\Delta$ is the angle between the nematic director $\mathbf{N}_{0}$ and the magnetic field $H_{0}$ and $B \approx 0.2 \mathrm{~s}^{-1}$. The temperature dependence of the angular dependence moreover shows the constant $C$ in eq. (4) to be nearly temperature independent - as expected for an ODF relaxation mechanism - whereas the $B$ term is thermally activated with an activation energy $E_{\mathrm{a}}=0.15 \mathrm{eV}$. Only below $100 \mathrm{G}$ there is a definite deviation from the « $\omega_{1}^{1 / 2} »$ law (Fig. 2) with $T_{1}$ becoming frequency independent as $\omega_{\mathrm{L}} \rightarrow 0$. Whereas the frequency dispersion of $T_{1}$ at high fields in the smectic A phase is practically identical to the one observed in nematic PAA [5], the low frequency deviation from the $" \omega_{\mathrm{L}}^{1 / 2} »$ law has not been observed [5] in the nematic phase.

The similarity of the dispersion in the nematic and the smectic phases is surprising in view of the large differences between these two mezophases and it seemed worthwhile investigating whether smectic fluctuation mechanisms can explain the observed frequency dependence of $T_{1}$. Whereas in the nematic phase the splay $\left(K_{1}\right)$, twist $\left(K_{2}\right)$ and bend $\left(K_{3}\right)$ elastic 
constants are all of the same order of magnitude [3] - so that the one elastic constant approximation $[1,4]$ $K_{1}=K_{2}=K_{3}=K$ can be made $-K_{2}$ and $K_{3}$ are in the smectic A phase generally [3] much larger than $K_{1}$. In the simplest model of the smectic A phase, proposed by Oseen [11] the only allowed deformation is the splay and we can in the nematic elastic free energy density [3]

$$
\begin{aligned}
g_{\mathrm{d}, \mathrm{n}}=\frac{1}{2} K_{1}(\operatorname{div} \mathbf{N})^{2}+\frac{1}{2} K_{2}(\mathbf{N} \operatorname{rot} \mathbf{N})^{2}+ & \\
& +\frac{1}{2} K_{3}(\mathbf{N} x \operatorname{rot} \mathbf{N})^{2}
\end{aligned}
$$

neglect the last two terms. In such a case the only allowed director fluctuations $\mathbf{N}=\mathbf{N}_{0}+\delta \mathbf{N}(\mathbf{r}, t)$ are undulations [3] of the smectic layers, where the interlayer distance is kept constant and the long molecular axes remain normal to the layers. It can be easily shown [10] that in this case

$$
\left(T_{1}\right)_{\mathrm{undul}, \xi=\mathrm{cst}} \propto \omega_{\mathrm{L}}
$$

if not cut-off frequency is introduced and if the coherence length $\xi_{z}$ perpendicular to the layers is assumed to be constant. If, however this coherence length is wave vector dependent [3]

$$
\xi_{z}=1 /\left(\lambda q_{\perp}^{2}\right),
$$

a logarithmic frequency dependence of $T_{1}$ is obtained $[10,12]$

$$
T_{1}^{-1} \propto \ln \left(1+\omega_{\mathrm{c}, \max }^{2} \mid \omega_{\mathrm{L}}^{2}\right)
$$

where only the upper cut-off frequency $[10,13]$ was taken into account. Both of these models can not explain the observed frequency and angular dependence of $T_{1}$ in the smectic A phase. The " $\omega_{\mathrm{L}}^{1 / 2}$ " law is, however, obtained, if all three terms in expression (5) are retained. Neglecting for sake of simplicity the cutoff frequencies, we find [10] the spectral density of dipole-dipole interactions modulated by director fluctuations as

$$
\begin{aligned}
J_{\mathrm{h}}(p \omega) & =\int_{-\infty}^{+\infty}<\left|F_{\mathrm{h}}(0) F_{\mathrm{h}}^{*}(t)\right|>\mathrm{e}^{-i \omega t} \mathrm{~d} t= \\
& =f_{\mathrm{h}}(\Delta) \cdot S^{2} \cdot \int_{-\infty}^{+\infty}<\delta \mathrm{N}(\mathbf{r}, 0) \delta \mathrm{N}(\mathbf{r}, t)>\mathrm{e}^{-i \omega t} \mathrm{~d} t \\
& =\frac{k T \cdot S^{2} \cdot f_{\mathrm{h}}(\Delta)}{4 \pi} \sum_{\alpha=1}^{2} \frac{\sqrt{2}}{K_{\alpha}} \sqrt{\frac{\eta_{\alpha}}{K_{3}}} \cdot \frac{1}{\sqrt{p \omega_{\mathrm{L}}}}
\end{aligned}
$$

where the $F_{\mathrm{h}}(t)$ are spherical harmonic functions describing the angular part of the dipolar interactions between a proton pair, and where all other symbols are defined in reference [10]. If, in addition to the nematic elastic free energy density, the smectic $\left(g_{\mathrm{sm}}\right)$ and the nematic-smectic interaction terms $g_{\mathrm{I}}$ are taken into account $[3,14]$

$$
\begin{aligned}
g_{\mathrm{d}} & =g_{\mathrm{d}, n}+g_{\mathrm{sm}}+g_{\mathrm{I}} \\
g_{\mathrm{sm}} & =a|\psi|^{2}+b|\psi|^{4}+\cdots \\
g_{\mathrm{I}} & =\left(\nabla+i q_{\mathrm{s}} \delta \mathbf{N}\right) \psi^{*} \frac{1}{2 M}\left(\nabla-i q_{\mathrm{s}} \delta \mathbf{N}\right) \psi
\end{aligned}
$$

the mean square director fluctuations [14] become

$$
\begin{aligned}
& \left\langle\left|N_{1 \mathrm{q}}\right|^{2}\right\rangle=\frac{k T}{K_{1} \cdot q_{\perp}^{2}+K_{3} \cdot q_{z}^{2}+\frac{\psi_{0}^{2} q_{\mathrm{s}}^{2}}{M} \cdot \frac{q_{z}^{2}}{q^{2}}} \\
& \left\langle\left|N_{2 \mathrm{q}}\right|^{2}\right\rangle=\frac{k T}{K_{2} \cdot q_{\perp}^{2}+K_{3} \cdot q_{z}^{2}+\frac{\psi_{0}^{2} \cdot q_{\mathrm{s}}^{2}}{M}}
\end{aligned}
$$

where

$$
q^{2}=q_{\perp}^{2}+q_{z}^{2}=q_{x}^{2}+q_{y}^{2}+q_{z}^{2},
$$

and the spectral density $J_{\mathrm{h}}(p \omega)-($ eq. (8)) - changes to :

$$
\begin{aligned}
& J_{\mathrm{h}}(p \omega) \approx f_{\mathrm{h}}(\Delta) \cdot S^{2} \cdot \frac{k T}{(2 \pi)^{2}} \frac{\pi}{K_{1}^{2} \cdot \sqrt{\delta \cdot K_{3} / K_{1}}} \times \\
& \times\left[\eta_{1} \cdot \frac{\sqrt{\frac{\omega_{\mathrm{c} 1}}{\omega_{\mathrm{L}}}}}{\sqrt{\frac{\omega_{\mathrm{c} 1}}{\omega_{\mathrm{L}}}+\sqrt{\left(\frac{\omega_{\mathrm{c} 1}}{\omega_{\mathrm{L}}}\right)^{2}+1}}}\right. \\
& \left.+\frac{\eta_{2}}{\sqrt{2}} \frac{\sqrt{\frac{\omega_{\mathrm{c} 2}}{\omega_{\mathrm{L}}}}}{\sqrt{\frac{\omega_{\mathrm{c} 2}}{\omega_{\mathrm{L}}}+\sqrt{\left(\frac{\omega_{\mathrm{c} 2}}{\omega_{\mathrm{L}}}\right)^{2}+1}}}\right] .
\end{aligned}
$$

Here

$$
\omega_{\mathrm{c} 1}=\delta / 2 p \eta_{1}, \quad \omega_{\mathrm{c} 2}=\delta / p \eta_{2}, \quad \delta=\psi_{0}^{2} . q_{\mathrm{s}} / M,
$$

$\psi_{0}$ is the equilibrium value of the smectic order parameter, $q_{\mathrm{s}}=2 \pi / d$ measures the distance $d$ between the smectic layers, the mass tensor $M$ has been replaced by a scalar quantity [14], and in a part of the integral over the Brillouin zone the isotropic $q$ approximation was used. The frequency dependence of

$$
T_{1}^{-1}=\text { const }\left[J_{1}\left(\omega_{L}\right)+J_{2}\left(2 \omega_{L}\right)\right]
$$

is still given by expression (3) as long [14] as $\omega_{\mathrm{L}} \gg \delta / \eta$. As soon as $\omega_{\mathrm{L}} \ll \delta / \eta, T_{1}$ becomes frequency independent [14] and approaches a constant value. Thus not only the $\left\langle\omega_{\mathrm{L}}^{1 / 2}\right.$ » dispersion law but also the low frequency deviations from it can be in principle explained by nematic director fluctuations in the smectic phase and the coupling between nematic and smectic order.

Brochard [14] estimates that the cross-over between the two above cases occurs for

$$
\omega_{\mathrm{L}} \approx 10^{11}\left[\frac{\Delta T}{T}\right] \mathrm{Hz},
$$

i. e. between $10^{9}$ and $10^{10} \mathrm{~Hz}$. In the present case, $T_{1}$ 
was found to follow the $" \omega_{L}^{1 / 2} 》$ law down to below $10^{6} \mathrm{~Hz}$, where it starts to become frequency independent.

Investigations of other smectic A systems - like alkyloxy-benzoic acid-nitro-phenyl ester and certain lamellar lyotropic systems [15] - yielded similar results showing that the observed dispersion law is characteristic not only for TBBA but may be a general property of the smectic A phase.

A more detailed discussion of the dispersion and angular dependence of $T_{1}$ in the low temperature smectic phases will be presented elsewhere.

\section{References}

[1] Pincus, P., Solid State Commun. 7 (1969) 415.

[2] Blinc, R., Hogenboom, D. L., O'Reilly, D. E. and Peterson, E. M., Phys. Rev. Lett. 23 (1969) 969.

[3] De GenNes, P. G., The Physics of Liquid Crystals (Clarendon Press, Oxford) 1974.

[4] Doane, J. W., Tarr, C. E. and Nickerson, M. A., Phys. Rev. Lett. 33 (1974) 622

[5] Wölfel, W., NoACK, F. and Stohrer, M., Z. Naturforsch. 30a (1975) 437, and references therein.

[6] Harmon, J. F. and Müller, B. N., Phys. Rev. 182 (1969) 400.

Vilfan, M., Blinc, R. and Doane, J. W., Solid State Commun. 11 (1972) 1073.

[7] Doucet, J., Levelut, A. M. and Lambert, M., Phys. Rev. Lett. 32 (1974) 301.
[8] See, for instance Goldman, Spin Temperature and Nuclear Magnetic Resonance in Solids (Clarendon Press, Oxford) 1970.

[9] Deloche, B., Charvolin, J., Liébert, L. and StrzeLECKI, L., J. Physique Colloq. 36 (1975) C 1-21.

[10] Blinc, R., Luzar, M., Vilfan, M. and Burgar, M., $J$. Chem. Phys. 63 (1975) 3445.

[11] Oseen, C. W., Trans. Faraday Soc. 29 (1933) 883.

[12] This result has been independently derived as well by DOANE, J. W.

[13] Doane, J. W., Tarr, C. E. and Nickerson, M. A., Phys. Rev. Lett. 33 (1974) 620.

[14] Brochard, F., J. Physique 34 (1973) 411.

[15] Unpublished work from this laboratory. 